http://jmscr.igmpublication.org/home/ ISSN (e)-2347-176x ISSN (p) 2455-0450 crossref DOI: https://dx.doi.org/10.18535/jmscr/v9i12.27

\title{
Clinicopathological Profile and Treatment Outcomes of Ameloblastoma- A Single Institution Experience
}

\author{
Authors \\ Dr Anila. K.R., DNB (Pathology) ${ }^{1^{*}}$, Dr Lakshmi Rajagopal, MD (Pathology) ${ }^{2}$, \\ Dr Sindhu Nair P, DNB (Pathology) ${ }^{3}$, Dr Thara Somanathan, MD (Pathology) ${ }^{4}$, \\ Dr Shaji Thomas, $\mathrm{MCh}^{5}$, Dr Venugopal M, $\mathrm{MD}^{6}$ \\ ${ }^{1}$ Associate Professor, Department of Pathology, Regional Cancer Centre, Thiruvananthapuram \\ ${ }^{2}$ Fellow in Oncopathology, Department of Pathology, Regional Cancer Centre, Thiruvananthapuram \\ ${ }^{3}$ Assistant Professor, Department of Pathology, Regional Cancer Centre, Thiruvananthapuram \\ ${ }^{4}$ Additional Professor, Department of Pathology, Regional Cancer Centre, Thiruvananthapuram \\ ${ }^{5}$ Additional Professor, Department of Surgical Oncology, Regional Cancer Centre, Thiruvananthapuram \\ ${ }^{6}$ Professor and Head, Department of Radiodiagnosis, Regional Cancer Centre, Thiruvananthapuram \\ *Corresponding Author \\ Dr Anila.KR
}

Associate Professor, Department of Pathology, Regional Cancer Centre, Thiruvananthapuram,

Kerala-695011,India

\begin{abstract}
Introduction: Ameloblastoma is a benign slow growing tumour of odontogenic origin. How-ever, they are locally aggressive and can cause severe deformities of face. Surgery with adequate margins is the standard treatment.

Objective: This study aims to report the clinicopathologic and follow-up details of patients with ameloblastoma treated at a tertiary care centre.

Materials and Methods: This was a retrospective study where-in archived data of patients histologically diagnosed with ameloblastoma between January 2010 and December 2020 at our centre were retrieved. Information on demographic details, clinicopathologic features, treatment modality, follow- up period, and recurrence were obtained. This study had approval of the institutional review board of our institute.

Results: A total of twenty-one patients were included in this study. Male preponderance was noted. Age predisposition was seen in the fourth decade. Most common site of involvement was posterior aspect of mandible. Most common histologic sub-type was follicular type. Radical surgery was the treatment done in most of the cases due to large size of tumour. Recurrences were noted as late as after 48 years of initial surgery.

Conclusion: Ameloblastoma though benign can attain huge sizes requiring radical surgery. Recurrences can occur many years after initial diagnosis, hence patients need to be kept on follow-up for long durations, preferably lifelong.

Keywords: Ameloblastoma, mandible, clinicopathologic features, recurrence.
\end{abstract}




\section{Introduction}

Odontogenic tumours are a rare group of benign and malignant neoplasms which arises from the tissue involved in odontogenesis. They are described in three locations; intraosseous in the jaw, extra osseous in the gingival or buccal mucosa and in the cranial base ${ }^{[1-2]}$. Ameloblastoma is a benign, intra-osseous progressively growing epithelial odontogenic neoplasm, characterized by expansion and a tendency for local recurrence if removal is not adequate. Ameloblastoma was first described by Cusak in 1827; how-ever the terminology ameloblastoma was first suggested by Ivy and Churchill in 1960, based on its odontogenic origin. ${ }^{[3]}$ Classical presentation of ameloblastoma is as a slow, painless expansion of jaw bones, wherein the absence of timely intervention leads to massive expansion with deformity of face, pain, loosening of teeth and serious complications.

Radiographically the classical appearance is a corticated multilocular soap bubble or honey comb radiolucency. ${ }^{[4]}$ The primary line of management is surgery, often requiring radical surgical procedures with adequate margin clearance. The aim of our study was to analyze the clinical, radiological, pathological characteristics and out-come of ameloblastoma treated in our centre during the period from January 2010 to December2020.

\section{Materials and methods}

Records of patients diagnosed with ameloblastictumors; ameloblastoma, metastasizing ameloblastoma, ameloblastic carcinoma who had treatment at our centre between January 2010 and December 2020, were retrieved from the pathology archives and consult filesof our institute. Patients who were diagnosed as cases of ameloblastoma, treated and under follow-up in our centre, as well as patients who had initial diagnosis and surgery at out-side centres, who presented to our centre with recurrences and had undergone further treatment and follow-up at our centre during the study period were also included in this study. Two cases of ameloblastic carcinoma and two cases of metastasizing ameloblastoma were excluded from the study. After applying inclusion and exclusion criteria there were twenty-one patients who were included in the study group. The medical records of all these patients were reviewed. Information on demographic details, clinical presentation, radiological details, surgical procedures and follow-up details, including recurrences were retrieved. The histopathology slides of the cases were reviewed for histopathology features, including histopathologic types and presence of aggressive features. The follow up clinical status was updated till June 2021. This study had approval from our institutional review board.

\section{Results}

A total of twenty-one patients were included in this study. There were fifteen males $(68 \%)$ and six females $(32 \%)$ with a male to female ratio of 2.1:1. The age ranged from 15-60 years with a mean age of 44.24 years and median age of 46years [Figure 1].Duration of onset of symptoms to first medical consultation ranged from 6months to as long as 8 years. Medical help was sought by most of the patients following recent increase in size of a long -standing swelling. The duration of recent increase in size ranged from 2 to 8 months. 


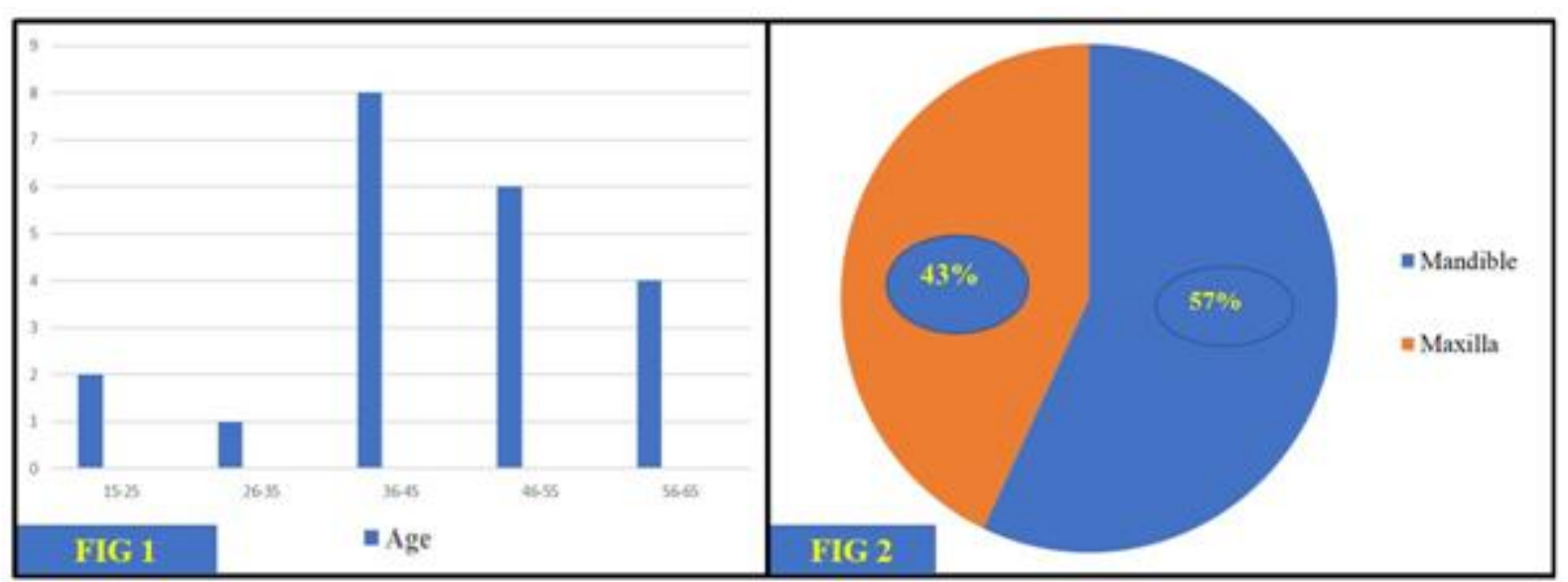

Figure1 Age distribution of cases in the present study

Figure 2 Depicts proportion of cases involving mandible and maxilla

There was almost equal distribution of tumors on both sides, with 12 cases on right side and nine cases on left side. Most of the cases had involvement of mandible i.e., 12 cases (57\%), while maxilla was involved in9 cases (43\%) [Figure 2]. Most of the mandible tumors were located posteriorly $(63 \%)$.

Majority of the mandibular cases in the present study presented radiologically as a lucent area in the angle of mandible. An expansile lucent area, well defined and well demarcated with corticated and scalloped margins, the scalloped margins giving the appearance of " honey- combing" or " soap bubbles" was the radiological feature observed in our cases.[Figure 3a] Unerupted third molar tooth was seen in an occasional case in relation to the lucency.

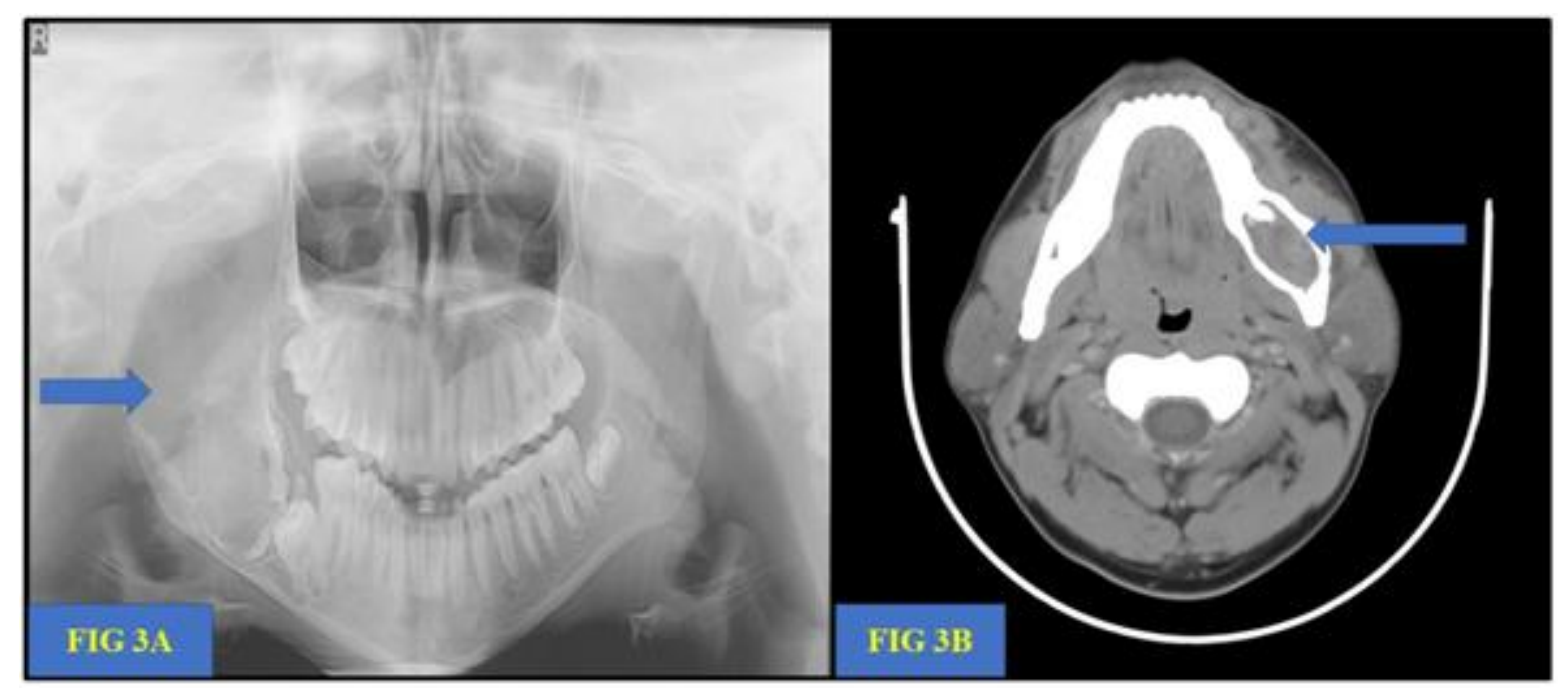

Figure 3a Expansile lucent area, well defined and well demarcated with corticated and scalloped margins, the scalloped margins giving the appearance of honey-combing

Figure 3b CT scan showing expansile lytic area with thinned out, scalloped cortical margins in the angle of mandible

In cases involving maxilla, the lucency was not as well defined as in mandible. Most of the cases showed lucency in the maxillary alveolar process, with extension in to the sinonasal cavity, making the latter opaque in radiography. Occasional cases showed destruction of the cortical bone because of the large size. 
In computerized tomography scan (CT scan) the lesions presented as expansile lytic area with thinned out, scalloped cortical margins or with cortical destruction, extending to the surrounding soft tissue, in the angle of mandible. [Figure 3b]In maxilla, there was creeping of the lysis in the alveolar process along the sinus walls, making the lesions less distinct with extension into the sinonasal cavity. Destruction of the sinus walls with extension to pre maxillary space, retro maxillary space, nasal cavity, upper gingivo-buccal sulcus, ethmoidal sinus, orbital cavity and into the oral cavity were noted

In magnetic resonance imaging (MRI) the cystic component were $\mathrm{T} 1$ hypointense, $\mathrm{T} 2$ hyperintense, signal suppressed in T2 FLAIR (T2-weightedFluid-Attenuated Inversion Recovery), hypo enhancing with no restricted diffusion. Whereas, the solid component was T1 isointense, T2 slightly hyperintense, signal not suppressed in $\mathrm{T} 2$ FLAIR, enhancing with intravenous contrast, showing restricted diffusion with low ADC (Apparent diffusion coefficient) values.

Surgery was the primary line of management in twenty cases. Most of these cases required radical surgery procedures due to large size of the tumor. Depending on the site and extent of disease, mandibular tumors were treated with wide excision along with marginal, segmental, hemi or arch mandibulectomy. [Figure 4] The most common procedure for maxillary tumors was subtotal maxillectomy. How-ever some cases required near total or total maxillectomy. One patient where-in surgery was not feasible due to co-morbidities was given radiotherapy. Of the twenty cases managed surgically, nine patients had their primary surgery and follow-up at our center. Eleven patients had initial definitive surgery at other centers, out of which nine patients developed recurrence during follow-up and were referred to our center for subsequent surgery and follow-up. Two patients came to our centre for follow-up.

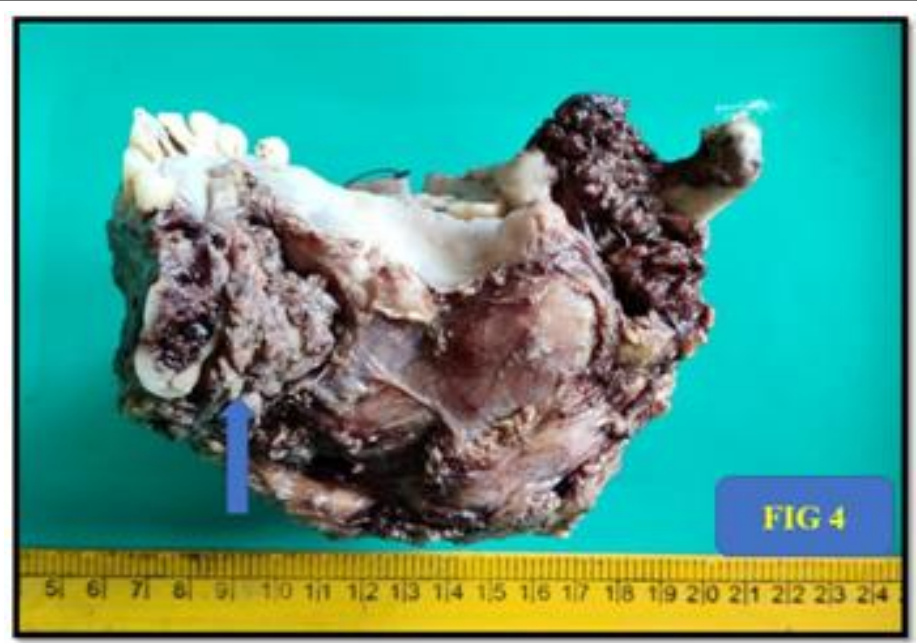

Figure 4 Extended hemi mandibulectomy specimen showing growth involving mandible

The most common histopathologic type in our study group was follicular type which was seen inten cases. There were four cases of plexiform type followed by two cases of acanthomatous type andtwo cases of granular type. [Figure 5] Three cases showed both follicular and acanthomatous patterns.

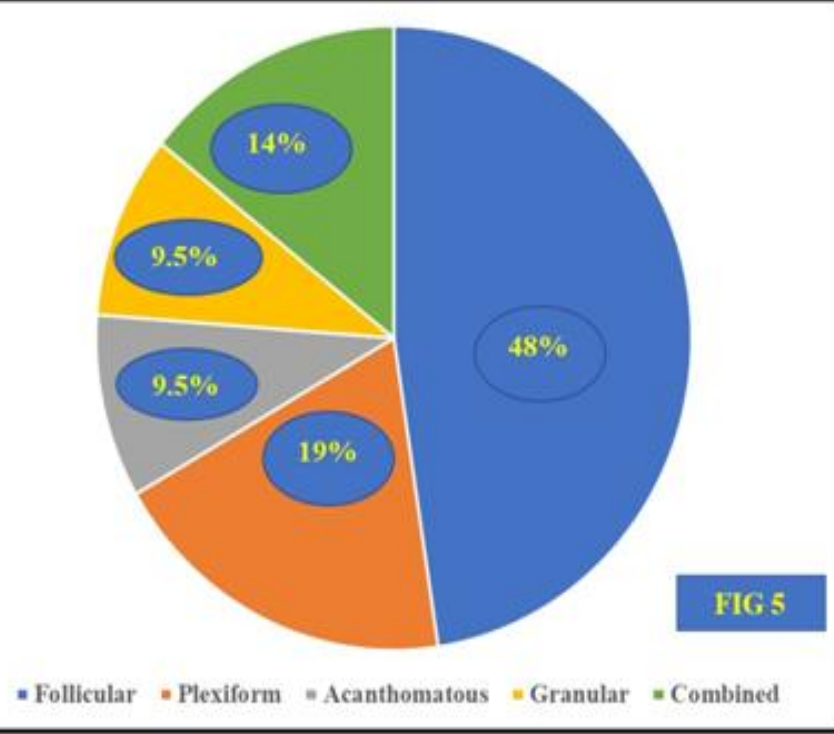

Figure 5 Depicts proportion of histopathologic subtypes of ameloblastoma

The follicular type consisted of is lands of odontogenic epithelium with columnar peripheral cells with hyperchromatic nucleus with palisading and reverse polarity. The inner cells resembled stellate reticulum. [Figure 6a]The plexiform type showed anastomosing strands and cords of cells. 
[Figure 6b] The acanthomatous type showed squamous metaplasia in the stellate-reticulum like areas. [Figure 6c] The granular type showed extensive granular cell change in the stellatereticulum like area. [Figure 6d]

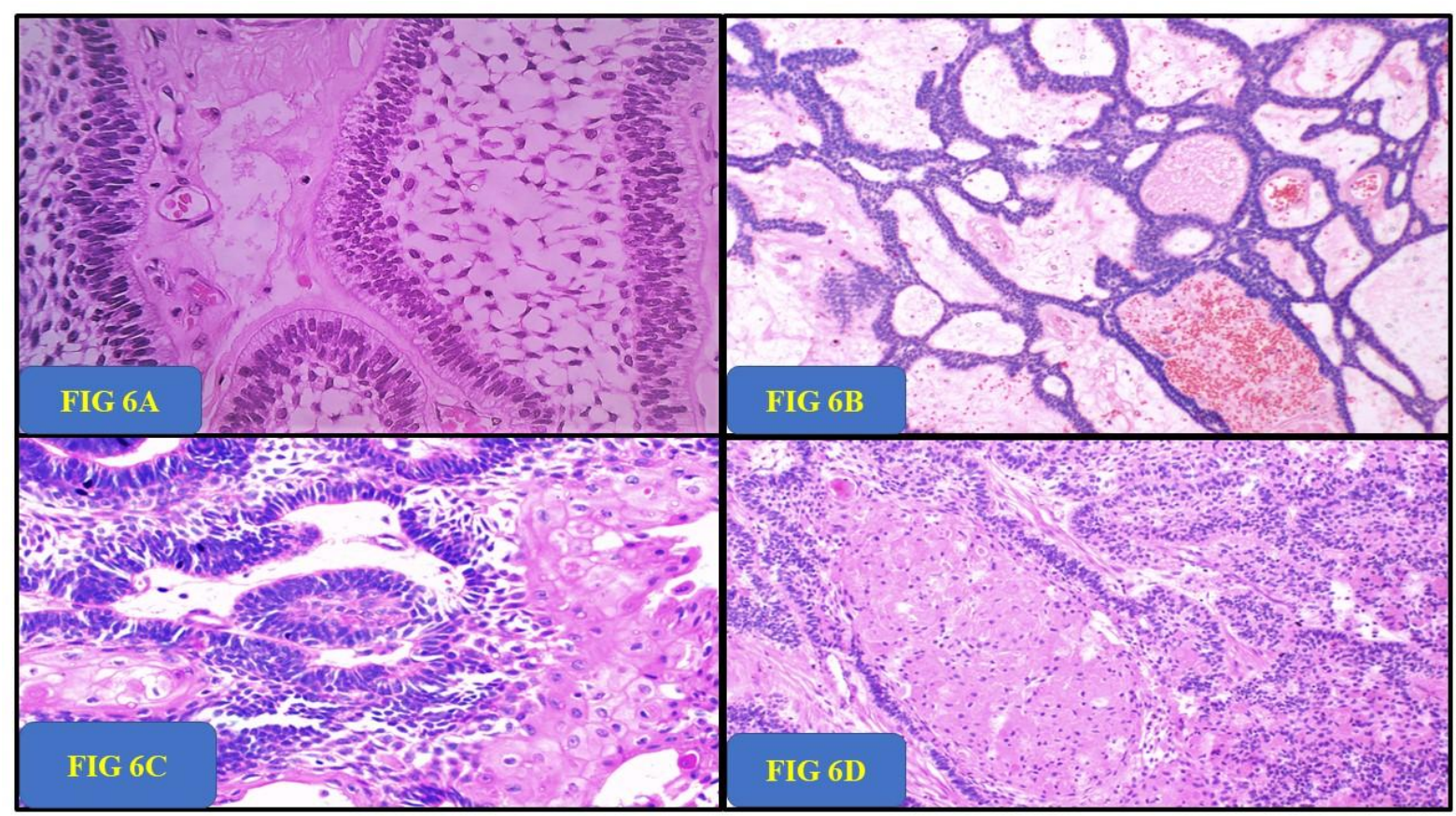

Figure 6a Follicular sub-type consisting of islands of odontogenic epithelium with columnar peripheral cells with hyperchromatic nucleus with palisading and reverse polarity. The inner cells resembling stellate reticulum.

Figure 6b Plexiform type showing anastomosing strands and cords of cells.

Figure 6c Acanthomatous type showing squamous metaplasia in the stellate-reticulum like areas.

Figure 6d Granulartype showing extensive granular cell change in the stellate-reticulum like area.

The duration of follow-up when up-dated till June 2021 ranged from two months to 84 months. The nine patients who had their primary surgery at our center had a follow-up period ranging from one year to seven years. During this period there was no recurrence. Two of these patients were given post-operative radiotherapy for close margins. The nine patients who had presented to us with recurrence had recurrence ranging from after 2 years of initial surgery to as late as 48 years after initial surgery.

\section{Discussion}

In this study most of the cases presented in the fourth decade. This is similar to the observations in previous studies by Kim and Jang, Hasegawa et al., Carvalho et al and Shoor et al. ${ }^{[5-8]}$ Amale preponderance with a male to female ratio of 2.1:1 was noted in this study, whichis also in concordance with the observations of previous studies in the literature by Tatapudi et al., Ibikunle et al, Selvamani et al., and Oomens and Van der Waal. ${ }^{\left[{ }^{[-12]}\right.}$ Most Indian studies have shown a male predominance. ${ }^{[7]}$

Most of the cases had involvement of mandible; $57 \%$, while maxilla was involved in $43 \%$. Most of the mandibular tumors were located posteriorly $(63 \%)$. This observation is similar to previous studies showing a predilection for posterior mandible. ${ }^{[8]}$ Literature claims $80 \%$ of ameloblastomas to occur in mandible. ${ }^{[13]}$ Among the histopathological subtypes follicular variant was the most common (48\%), followed by plexiform variant. Almost all studies in the literature have observed follicular variant to be the most common sub-type. ${ }^{[14-16]}$ 
Ameloblastoma has got characteristic, but not diagnostic, features in radiography. The radiographic appearances that have been most commonly described in the literature

are the unilocular and multilocular appearances. ${ }^{[17,18]}$ Variants of the multilocular radiographic appearance include soap bubble and honeycomb appearances which were observed in our series also.It was also observed in the present study that in cases involving maxilla, the lucency was not as well defined as in mandible. MRI and CT scan are said to be superior in the delineation and characterization of ameloblastoma. ${ }^{[4]} \mathrm{How}-$ ever in the present study it was noted that in CT scan of lesions involving maxilla, there was creeping of the lysis in the alveolar process along the sinus walls, making the lesions less distinct than mandibular lesions.

Surgical resection with adequate margin clearance is the standard line of management for ameloblastoma. Different treatment options that are currently practised include marsupialization, enucleation, enucleation along with treatment of surrounding bone,

and surgical resection depending on extent of disease. ${ }^{[19]}$ Conservative management is done for less aggressive variants like unicystic ameloblastoma. How-ever whenever conservative management is done, the patient should be kept on close follow-up to detect recurrences at the earliest. In our study, patients had to be managed with radical surgeries mostly due to the large size of the tumor. Patients who presented at our center with recurrences after primary surgeries out -side were also managed with radical revision surgeries. Cases wherein adequate margin clearance was not possible or where close were given post-operative radiotherapy.

Recurrence in ameloblastoma is well documented in literature. ${ }^{[20]}$ In most of the studies in the literature on ameloblastoma, recurrences especially in the posterior aspect of jaw bones were observed. In the present study we had nine patients who had their primary surgery at peripheral centres presenting to us with recurrences. The recurrences occurred within a period of two years of initial surgery to as late as 48 years after initial surgery.

\section{Conclusion}

Ameloblastoma is a benign, intra-osseous progressively growing epithelial odontogenic neoplasm, characterized by expansion and a tendency for local recurrence. Delay in seeking medical help, as observed in this study can result in large sized, locally aggressive tumours wherein complete resections with adequate margins can be difficult to achieve. Recurrences in ameloblastoma are well documented and are known to occur years after initial surgery. This highlights the importance of keeping patients on follow-up for a long period of time.

\section{References}

1. DG, Heikinheimo $K$, Shear $M$, et al. Ameloblastomas. In: Barnes L, Eveson JW, Reichart P, et al. Eds. World Health Organization Classification of Tumours. Pathology and Genetics of Head and Neck Tumours. Lyon: IARC Press, 2005:296300.

2. Shear M, Singh S. Age-standardized incidence rates of ameloblastoma and dentigerous cyst on the Witwatersrand, South Africa. Community Dent Oral Epidemiol 1978; 6:195-99.

3. Oliveira LR, Matos BH, Dominguete PR, Zorgetto VA, Ribeiro-Silva A. Ameloblastoma: Report of two cases and a brief literature review. IntJ Odontostomatol 2011; 5:293-9.

4. More C, Tailor M, Patel HJ, Asrani M, Thakkar K, Adalja C, et al.Radiographic analysis of ameloblastoma: A retrospective study.Indian J Dent Res 2012; 23:698.

5. Kim SG, Jang HS. Ameloblastoma: A clinical, radiographic, andhistopathologic analysis of 71 cases. Oral Surg Oral Med Oral Pathol Oral Radiol Endod 2001; 91:649-53. 
6. Hasegawa T, Imai Y, Takeda D, Yasuoka D, Ri S, Shigeta T, et al. Retrospective study of ameloblastoma: The possibility of conservativetreatment. Kobe J Med Sci 2013;59: E112-21.

7. Shoor H, Pai KM, Gupta S, Garg A, Sharma H, Kumar N. Clinical,radiographic and histopathologic features of ameloblastoma:A retrospective analysis of 21 cases. Int J Sci Stud 2014; 2:83-8.

8. Carvalho KM, Dhupar A,Spadigam A, Syed S. Ameloblastoma: A 16yearclinicopathological study on Goan population. Indian $\mathbf{J}$ Pathol Microbiol 2017; 60:157-60.

9. Tatapudi R, Samad SA, Reddy RS, Boddu NK. Prevalence ofameloblastoma: A three- year retrospective study. J Indian AcadOral Med Radiol 2014; 26:145.

10. Selvamani M, Yamunadevi A, Basandi PS, Madhushankari GS.Analysis of prevalence and clinical features of multicystic ameloblastoma and its histological subtypes in South Indian sample population: A retrospective study over 13 years. J Pharm Bioallied Sci 014;6: S131- 4.

11. Oomens MA, van der Waal I. Epidemiology of ameloblastomas of the jaws; a report from the Netherlands. Med Oral Patol Oral Cir Bucal 2014;19: e581- 3 .

12. Ibikunle AA, Taiwo OA,Braimah RO, Adeyemi M, Abdullahi K, Sahabi SM. Ameloblastoma: Clinicopathologic and therapeutic analysis of 67 cases seen at Usmanu Danfodiyo University Teaching Hospital Sokoto, Nigeria. Int JHealth Allied Sci 2018;7:240-5.

13. de Moraes FB, Cardoso RM, Rodrigues SV, Dutra MV, Pereira UR,Borges TR. Ameloblastoma: A clinical and therapeutic analysis on sixcases. Rev Bras Ortop 2014; 49:305-8.

14. Adebiyi KE, Ugboko VI, Omoniyi- Esan GO, Ndukwe KC,Oginni FO. Clinicopathological analysis of histological variants of ameloblastoma in a suburban Nigerian population. Head FaceMed 2006; 2:42.

15. Ladeinde AL, Ogunlewe MO, Bamgbose BO, Adeyemo WL,Ajayi OF, Arotiba GT, et al. Ameloblastoma: Analysis of 207 casesin a Nigerian teaching hospital. Quintessence Int 2006; 37:69- 74.

16. Naik BR. Clinicopathological study of ameloblastomas: Case study intribal areas. Int J Head Neck Surg 2011; 2:1-4.

17. McClary AC, West RB, McClary AC, Pollack JR, Fischbein NJ,Holsinger CF, et al. Ameloblastoma: A clinical review and trendsin management. Eur Arch Otorhinolaryngol 2016; 273:1649- 61.

18. Olusanya AA, Adisa AO, Lawal AO, Arotiba JT. Gross surgical features and treatment outcome of ameloblastoma at a Nigerian tertiary hospital. Afr J Med Med Sci 2013; 42:59- 64.

19. Dandriyal R, Gupta A, Pant S, Baweja HH. Surgical management of ameloblastoma: Conservative or radical approach. Natl J Maxillofac Surg 2011; 2:22- 7

20. Santos Tde S, Piva MR, Andrade ES, Vajgel A, Vasconcelos RJ, Martins- Filho $\mathrm{PR}$, et al. Ameloblastoma in the Northeast regionof Brazil: A review of 112 cases. J Oral Maxillofac Pathol2014;18: S66- 71. 